MANCHESTER

1824

†⿺

Economics

Discussion Paper Series EDP-1120

\title{
Simultaneous determination of market value and risk premium in the valuation of firms
}

\author{
Stefan Lutz
}

August 2011

Economics

School of Social Sciences

The University of Manchester

Manchester M13 9PL 


\title{
Simultaneous determination of market value and risk premium in the valuation of firms*
}

\author{
Stefan Lutz ${ }^{* *}$
}

27 July 2011

Valuing a firm using the discounted cash flow method (DCF) requires the joint determination of the market value of its equity (MVE) together with the equity risk premium (ERP) the firm should earn, since the latter is part of the discount rate used in the calculation of the MVE. This paper presents a theoretical derivation of how MVE and ERP can be calculated simultaneously under fairly general conditions. Besides firm data on free cash flow to equity the only external data needed are the risk-free rate of interest and a parameter indicating the required market risk premium per return volatility.

JEL classification: G1, G3, M4

Keywords: firm valuation, DCF, CAPM, risk premium, transfer pricing

\footnotetext{
* The views expressed in this paper are those of the author and do not necessarily reflect those of the institutions he is affiliated with. Any information presented is of a general nature and does not address individual circumstances of any particular person or entity. The author would like to thank Nils Holinski for helpful comments and suggestions as well as Nitish Maini and Keshav Goel for diligent research assistance; the usual disclaimer applies. Financial support by the International Centre for Economic Research (ICER), Torino, Italy, and by the Spanish Ministry of Education and Science (Grant No. ECO2008-06191) is gratefully acknowledged.

${ }^{* *}$ Dr. Stefan Lutz, stefan.lutz@manchester.ac.uk, is a Research Fellow at the University of Manchester, UK.
} 


\section{Introduction}

The discounted cash flow method ${ }^{1}$ (DCF) is frequently used for the valuation of firms or other assets. Since it consists of discounting future cash earnings, an appropriate discount rate needs to be applied. Such a discount rate would contain an individual equity risk premium (ERP) the firm should earn given its risk profile; such a risk premium is usually derived with recourse to the Capital Asset Pricing Model (CAPM). ${ }^{2}$

For publicly listed firms an estimate of the individual risk premium may be derived with the use of publicly available stock market data. Once the risk premium is known, the applicable discount rate is also known and the market value of equity (MVE) can be calculated. If the firm to be valued is not publicly listed, the risk premium and hence the applicable discount rate cannot be determined separately from and before determining the MVE. ${ }^{3}$ Nevertheless, such a risk premium can be derived from the firm's profit and loss and balance sheet data by examining the free cash flow to equity (FCFE).

This paper presents a theoretical illustration of how MVE and ERP can be calculated from a firm's own cash flow data. A general solution for the simultaneous determination of the MVE and ERP and conditions for its existence are derived. Applications for valuation of multi-national enterprises and in transfer pricing are discussed.

The remainder of the paper is structured as follows. Section 2 reviews common concepts of accounting for risk in firm valuation. The model and general solutions are presented in section

\footnotetext{
${ }^{1}$ See, e.g., Brealey/Myers/Allen (2006) chapters 4 or 8, Luenberger (1998) chapter 7 for an introduction. For a recent critical review see, e.g., Kruschwitz/Löffler (2005).

2 See Sharpe (1964), Treynor (1962), Lintner (1965), Mossin (1966), and Markowitz (1959). For more recent discussions see, e.g., Perold (2004), Fama/French (2004). For a multi-period extension, see Fama (1977), Mai (2006). For an exposition of the relationship between CAPM and option pricing see, Cesari/D'Adda (2003). For a reformulation of the CAPM relationship in terms of Sharpe ratios see Zakamulin (2011).

${ }^{3}$ This creates an apparent “circularity problem”. See, e.g., Schwetzler/Darijtschuk $(2000,1999)$.
} 
3. Section 4 discusses possible applications and conclusions. Auxiliary calculations are presented in the appendix.

\section{Background: accounting for risk in firm valuation}

When valuing firms by DCF, the crucial question is regularly the valuation of risky future cash flows; an approach frequently chosen involves discounting the cash flows by a discount rate including a risk premium such as can be derived using a CAPM approach. ${ }^{4}$

The discount rate represents the (opportunity) cost of capital invested; if the cash flows valued are those accruing to equity (FCFE), i.e. after deduction of any costs of debt financing, then the discount rate represents the cost of equity financing or the required (minimum) expected return on equity financing. ${ }^{5}$

Note that this interpretation implies a second role for the discount rate as cost of equity financing. Namely, the investor expects that future cash flows as a percentage of the market value of the equity invested (the MVE) will be at least as high. Hence when profits of individual firms are viewed as returns on equity invested, CAPM can also be used to compare individual firms' profits against a market benchmark. ${ }^{6}$

One of the main conclusions of the CAPM theory is that an adequate remuneration for the risks assumed by an equity investment is given by the market risk premium multiplied by the covariance of the returns on the equity invested with the market return. ${ }^{7}$

\footnotetext{
${ }^{4}$ See, e.g., Kruschwitz/Löffler (2005).

${ }^{5}$ FCFE is widely used and can be particularly useful for the valuation of firms with varying gearing (debt/equity financing) ratios. This normally requires detailed modeling of financing structure and interest charges when deriving the relevant cash flows. See, e.g., Shaw (2007), p. 15.

${ }^{6}$ This builds the basic for applications in transfer pricing - discussed in section 4 below - where arm's length (market) prices and profits should also include equity risk premia.

${ }^{7}$ This is illustrated in section 3 below; see in particular equations (1) and (2).
} 
Since that covariance contains a measure of the volatility of the returns on the equity invested, an adequate equity risk premium (ERP) is also a function of the volatility of the returns on the equity invested. In fact, empirical analyses using historical financial markets data show that the ERP paid by the capital market for the assumption of risk corresponds to a multiple of the standard deviation of the Returns on Equity $(\mathrm{RoE}){ }^{8}$

While these empirical results are derived from data on investments in financial markets, the same principles should also apply when an investor finances an enterprise directly. As a consequence, the pricing of an enterprise's products should be set such that the resulting profits can be expected to adequately remunerate the firm's equity investors for the risks they have taken in financing the enterprise. Recent research shows that this is in fact the case and that firm's average RoEs tend to increase with the volatility of those RoEs. ${ }^{9}$

\section{Modeling: simultaneous determination of market value and risk premium}

This section presents a simple theoretical model that can be solved simultaneously for the MVE and the ERP.

According to the standard convention in the CAPM, the required return for any asset $\mathrm{i}, \mathrm{r}_{\mathrm{i}}$, can be expressed as:

$$
r_{i}=r_{f}+\beta_{i}\left(r_{m}-r_{f}\right) \text { and } \quad \text { (2) } \quad \beta_{i}=\frac{\sigma_{i m}}{\sigma_{m}^{2}}=\frac{\rho_{i m} \sigma_{i} \sigma_{m}}{\sigma_{m}^{2}}
$$

where $r_{f}$ denotes the risk-free rate of interest, $r_{m}$ denotes the market return, $\sigma_{\text {im }}$ and $\rho_{\text {im }}$ denote the covariance and the correlation coefficient, respectively, between firm i's return on equity

\footnotetext{
${ }^{8}$ See, e.g., Damodaran (2008), Damodaran (2010).

${ }^{9}$ Lutz/Kleinfeldt (2010) analyzed a panel of about 160,000 firms for the years 1992 to 2007. When earnings are set in relation to invested capital, risk measured as earnings volatility emerges as the only stable determinant of income; firms with higher volatility of returns to shareholder funds tend to have higher average returns to shareholder funds.
} 
and the market return, $\sigma_{\mathrm{i}}$ denotes the standard deviation of asset i's return, $\sigma_{\mathrm{m}}$ denotes the standard deviation of the market return, and $\sigma^{2}$ denotes the variance of the market return.

Suppose asset $\mathrm{i}$ is a particular firm financed with a debt to equity ratio of $\delta^{10}$ and taxed at rate $\tau$, then equation (2) becomes ${ }^{11}$

$$
\beta_{i}=\left(1+(1-\tau) \delta_{i}\right) \frac{\rho_{i m} \sigma_{i} \sigma_{m}}{\sigma_{m}^{2}}
$$

define $\alpha_{\mathrm{i}}$ as:

$$
\alpha_{i}=\left(1+(1-\tau) \delta_{i}\right) \frac{\rho_{i m}}{\sigma_{m}}\left(r_{m}-r_{f}\right)
$$

For the firm $i$, let $\mathrm{C}_{\mathrm{i}}$ be its contemporary FCFE, $\mathrm{r}_{\mathrm{i}}$ its required return on equity (the applicable discount rate), and $g_{i}$ the expected growth rate of $C_{i}$. Firm i's market value of equity will then be given by $\mathrm{V}_{\mathrm{i}}$ :

(4) $\quad V_{i}=\frac{C_{i}}{\left(r_{i}-g_{i}\right)}$

Furthermore, let $\sigma_{\mathrm{Ci}}$ be the standard deviation of $\mathrm{FCFE}_{\mathrm{i}}$ then the required return on equity can be expressed as ${ }^{12}$

$$
r_{i}=r_{f}+\alpha_{i} \sigma_{C i}\left(\frac{1}{V_{i}}\right) \quad \text { where } \quad \text { (6) } \quad \sigma_{i}=\sigma_{C i}\left(\frac{1}{V_{i}}\right)
$$

\footnotetext{
${ }^{10}$ With a constant ratio of of debt to equity (in market values), the required return to equity will also be constant see, e.g., Velez-Pareja et al. (2008). With a constant and known return to equity, the market value of equity can be calculated - see, e.g., Schwetzler/Darijtschuk (1999).

${ }^{11}$ According to Modigliani/Miller (1958), equation (2) denotes the pure investment risk (captured by the "asset beta") whereas equation (2') also captures the additional financing risk due to debt financing - see also, e.g., Schwetzler/Darijtschuk (1999).

${ }^{12}$ Let the cash flow of period $\mathrm{t}$ be a random variable that grows at a yearly rate $\mathrm{g}_{\mathrm{ig}}$ but is otherwise serially independent; then both $\sigma_{\mathrm{Ci}}$ and $\sigma_{\mathrm{i}}$ are well-defined - see appendix A.1.
} 
Simultaneous solution of equations (4) and (5) then yields

(7) $\quad \nabla_{i}=\frac{C_{i}-\alpha \sigma_{C i}}{\left(r_{f}-g_{i}\right)} \quad$ and $\quad$ (8) $\quad \hat{r}_{i}=\frac{r_{f} C_{i}-g_{i} \alpha \sigma_{C i}}{C_{i}-\alpha \sigma_{C i}}$.

Note that equations (4) and (5) form a unique well-defined solution as long as the following parameter condition is satisfied:

$$
\forall r_{f}>(<) g_{i} ; C_{i}>(<) \alpha \sigma_{C i}{ }^{13}
$$

Condition (9) implies that for a well-defined solution to exist, a high-growth cash flow must also exhibit a relatively high volatility (and a low-growth cash flow a low volatility).

A proof for the uniqueness of the derived solution is given in appendix A.2.

\section{Application: conclusions for the valuation of multi-national firms}

The method presented above allows the application of the DCF modeling with FCFEs leading to the derivation of an adequate ERP directly from the firm's own cash flow data; the only external data needed are the risk-free rate of interest and a parameter indicating the required market risk premium per return volatility. This allows for consistent valuation of firms including of those firms that are not publicly listed and where ownership shares are not publicly traded.

Besides valuation of a firm given its cash flows this method also allows comparing the cash flows themselves to market returns on equally risky assets. This latter possibility is potentially useful in transfer pricing, where the profit levels of dependent subsidiaries of MNEs are frequently under investigation. OECD transfer pricing guidelines, i.e. taxation guidelines with respect to income that derives from controlled transactions between subsidiaries and/or with

\footnotetext{
${ }^{13}$ If condition (9) is violated, no positive-valued solution exists.
} 
owners within an MNE, stipulate that the pricing of these transactions and the resulting profits must be such that uncontrolled third parties would have agreed voluntarily to undertake such transactions; this is known as the arm's length standard. ${ }^{14}$ In principle this implies that prices for goods and services are set at market prices and that profits should earn a market return that adequately remunerates individual risk. ${ }^{15}$

Examples for applications in transfer pricing include the pricing of adequate remuneration of contract manufacturers in the automobile industry as well as the determination of adequate profit shares between several risk-bearing co-entrepreneurs within a multi-national enterprise ${ }^{16}$.

A numerical example is presented in appendix A.3 and illustrated graphically. In the example presented the following parameter values for firm i are chosen: a yearly cash flow of EUR 10m growing at a rate of $2 \%$ pa with a cash-flow volatility of EUR $5 \mathrm{~m}$ pa. Then with a risk-free rate of 5\% pa and a risk parameter of 1 , the market value of equity will be EUR $166.667 \mathrm{~m}$ and the cost of equity will be $8 \%$ pa. The risk premium will be $1 * 5 / 166.667=3$ percentage points.

The risk parameter of 1 is assumed to be estimated externally ${ }^{17}$; however, it can also be derived from underlying market parameters according to equation (2'). In our example, the parameters are: a debt/equity ratio of 1 , a tax rate of $30 \%$, a volatility of the market return of $5 \%$ pa, a market risk premium (the difference between market return and risk-free return) of 5\% pa, and a correlation between the firm's equity return and the market return of 0.588 .

\footnotetext{
${ }^{14}$ The arm's length standard for the assessment of transfer prices remains consensus among the OECD member states. See Para 1.6 and 1.12 of the OECD guidelines (OECD (1995/2001/2010)).

${ }^{15}$ OECD guidelines also prescribe that risk should be accounted for when determining international prices for goods and services between different subsidiaries of MNEs. Since the adequacy of transfer prices is most commonly measured by comparisons of profit-level indicators, such as profit after taxes, between independent firms and comparable subsidiaries of MNEs, the OECD principles also directly imply that risk should be accounted for when valuing resulting profits of such subsidiaries of MNEs. Compare Para 1.27 of the OECD guidelines (OECD (1995/2001/2010)). See Chapter IX of the OECD guidelines for new OECD considerations regarding business restructurings changing corporate risk profiles.

${ }^{16}$ See, e.g., Faß/Lutz (2009).

${ }^{17}$ See, e.g., Lutz/Kleinfeldt (2010) and Lutz (2011).
} 


\section{Literature}

Brealey, R., S. Myers and F. Allen (2006). Corporate Finance, $8^{\text {th }}$ ed. (McGraw-Hill, New York).

Cesari, R. and C. D'Adda (2003). "A Simple Approach to CAPM, Option Pricing and Asset Valuation”. Università die Bologna Working Paper DSE No. 467.

Damodaran, A. (2010), "Equity Risk Premiums (ERP): Determinants, Estimation and Implications - The 2010 Edition”, Stern School of Business, New York University.

Damodaran, A. (2008), "Equity Risk Premiums (ERP): Determinants, Estimation and Implications", Stern School of Business, New York University.

Fama, E. F. and K. R. French (2004). "The Capital Asset Pricing Model: Theory and Evidence", Journal of Economic Perspectives, 18(3), 25-46.

Fama, E. F. (1977). "Risk-adjusted Discount Rates and Capital Budgeting under Uncertainty”, in: Journal of Financial Economics, 5, 3 - 24.

Faß, A. and S. Lutz (2009). “Co-Entrepreneur-Modell”, Controlling, 21(11), 591-597.

Kruschwitz, L. And A. Löffler (2005). "Ein neuer Zugang zum Konzept des Discounted CashFlow“, Journal für Betriebswirtschaft, 55, 21-36.

Lintner, J. (1965). “The Valuation of Risk Assets and the Selection of Risky Investments in Stock Portfolios and Capital Budgets", Review of Economics and Statistics, 47, 13-37.

Luenberger, D. (1998). Investment Science (Oxford University Press, New York).

Lutz, S. (2011). "Risk premia in multi-national enterprises", International Centre for Economic Research (ICER), Torino. 
Lutz, S. and D. Kleinfeldt (2010). "Risk as determinant of income and cross-border pricing of multi-national enterprises”, University of Manchester Economics Discussion Paper EDP1018, University of Manchester, UK.

Mai, J.M. (2006). "Mehrperiodige Bewertung mit dem Tax-CAPM und Kapitalkostenkonzept“"Zeitschrift fur Betriebswirtschaft, 76(12), 1225-1253.

Markowitz, H. (1959). Portfolio Selection: Efficient Diversification of Investments, Cowles Foundation, Monograph No. 16 (John Wiley \& Sons, Inc., New York).

Modigliani, F. and M. H. Miller (1958). "The Cost of Capital, Corporation Finance, and the Theory of Investment", American Economic Review, 48:3, 261-97.

Mossin, J. (1966). “Equilibrium in a Capital Asset Market” Econometrica, 35, 768-83.

OECD (1995/2001/2010). „Transfer Pricing Guidelines for Multinational Enterprises and Tax Administrations“, published 22 July 2010.

Perold, A. F. (2004). “The Capital Asset Pricing Model”, Journal of Economic Perspectives, $18(3), 3-24$.

Schwetzler, B. and N. Darijtschuk (2000). "Unternehmensbewertung und Finanzierungspolitiken“, Zeitschrift für Betriebswirtschaft, 70(1), 117-134.

Schwetzler, B. and N. Darijtschuk (1999). "Unternehmensbewertung mit Hilfe der DCFMethode--Eine Anmerkung zum "Zirkularitatsproblem“, $\underline{\text { Zeitschrift für }}$ Betriebswirtschaft, 69(3), 295-318.

Sharpe, W. F. (1964). "Capital Asset Prices: A Theory of Market Equilibrium Under Conditions of Risk", Journal of Finance, 19, 425-42.

Shaw, S. (2007). "Valuing Companies", Steve Shaw Associates, Workshop Script, Version 2007.01. 
Treynor, J. L. (1962). “Toward a Theory of Market Value of Risky Assets”, unpublished manuscript. Final version in: Korajczyk, R. A. (ed.)(1999). (Asset Pricing and Portfolio Performance (Risk Books, London), 15-22.

Velez-Pareja, I., Ibragimov, R., Tham, J.(2008). “Constant Leverage and Constant Cost of Capital: A Common Knowledge Half-Truth”, Estudios Gerenciales, 24(107), 13-33

Zakamulin, V. (2011). "Sharpe (Ratio) Thinking about the Investment Opportunity Set and CAPM Relationship”, Economics Research International, in Press (accepted 4 May 2011) 


\section{Appendix}

\section{A.1. DCF volatility}

Derivation of the variance of the market value of equity given constant growth in expected cash flows and their volatilities. Let the cash flow of firm $i$ in period $t_{j}$ be
(A.1.1) $C_{i t_{j}}=\left(1+g_{i}\right)^{t_{j}} C_{i 0}$

where $\mathrm{C}_{\mathrm{i} 0}$, the cash flow in period 0 , is a random variable. Then the variance of the market value of equity is given as ${ }^{18}$

(A.1.2) $\sigma_{V_{i}}^{2}=\frac{1}{\left(1+r_{i}\right)^{2}} \sum_{t_{j}=0}^{\infty} \sum_{t_{k}}^{\infty}\left(\frac{1}{1+r_{i}}\right)^{t_{j}+t_{k}} \operatorname{Cov}\left(C_{i t_{j}}, C_{i t_{k}}\right)$

(A.1.3) $\sigma_{V_{i}}^{2}=\frac{1}{\left(1+r_{i}\right)^{2}} \sum_{t_{j}=0}^{\infty} \sum_{t_{k}}^{\infty}\left(\frac{1+g_{i}}{1+r_{i}}\right)^{t_{j}+t_{k}} \operatorname{Cov}\left(C_{i 0}, C_{i 0}\right)$

(A.1.4) $\sigma_{V_{i}}^{2}=\frac{1}{\left(1+r_{i}\right)^{2}} \sum_{t_{j}=0}^{\infty} \sum_{t_{k}}^{\infty}\left(\frac{1+g_{i}}{1+r_{i}}\right)^{t_{j}+t_{k}} \sigma_{C_{i 0}}^{2}$

(A.1.5) $\sigma_{V_{i}}^{2}=\frac{1}{\left(g_{i}-r_{i}\right)^{2}} \sigma_{C_{i 0}}^{2}$

and the standard deviation as

(A.1.6) $\sigma_{V_{i}}=\frac{1}{\left(g_{i}-r_{i}\right)} \sigma_{C_{i 0}}$

Hence we have:

(A.1.7) $\sigma_{C_{i t_{j}}}=\left(1+g_{i}\right)^{t_{j}} \sigma_{C_{i 0}}$.

${ }^{18}$ Using the end-of-period convention and noting that $\operatorname{Cov}(\mathrm{a} X, \mathrm{~b} Y)=\mathrm{a} b \operatorname{Cov}(\mathrm{X}, \mathrm{Y})$. 
The volatilities (standard deviations) of the firm value and the cash flows are proportional to their respective discounted expected values. This corresponds to the heteroskedasticity often exhibited by empirical data.

\section{A.2. Uniqueness of the solution for MVE and RoE}

To show uniqueness of the solution given in equations (7) and (8), we compare the curvature of the cost-of-equity equation (6) with that of the inverse of the market-value-of-equity equation (5) which is given by

$$
\text { (A.2.1) } \quad V_{i}^{-1}\left(r_{i}\right)=r_{i}^{i n v}=\frac{C_{i}}{V_{i}}+g_{i}
$$

The first derivatives of equations (A.2.1) and (6) with respect to the market value of equity are given by:
(A.2.2)

$$
\frac{\partial r_{i}^{i n v}}{\partial V_{i}}=-\frac{C_{i}}{V_{i}^{2}}
$$
and
(A.2.3) $\frac{\partial r_{i}}{\partial V_{i}}=-\alpha_{i} \frac{\sigma_{C i}}{V_{i}^{2}}$, respectively.

Note that given condition (9), equations (A.2.1) and (6) have an intersection given by equations (7) and (8). Furthermore, given equation (9) we have

$$
-\frac{C_{i}}{V_{i}^{2}}<(>)-\alpha_{i} \frac{\sigma_{C i}}{V_{i}^{2}},
$$

i.e. equations (A.2.1) and (6) intersect only once. QED

\section{A.3. Numerical example and graphical illustrations}

To solve for the market value of equity $V_{i}$ and the cost of equity $r_{i}$ simultaneously, we solve equations (4) and (5) simultaneously. This corresponds to finding graphically the unique 
intersection between the two equations. In order to show them together in a single figure, one of them has to be inversed. Hence, define the inverse of equation (5) as

$$
r_{i}^{-1}\left(V_{i}\right)=V_{i}^{i n v}=\frac{\alpha \sigma_{C i}}{r_{i}-r_{f}}
$$

Then we can show equations (4) and (A.3.1) as well as the equilibrium solution graphically. ${ }^{19}$ For a yearly cash flow of EUR $10 \mathrm{~m}$ growing at a rate of $2 \%$ pa with a cash-flow volatility of EUR $5 \mathrm{~m}$ pa, a risk-free rate of 5\% pa and a risk parameter of 1 , the market value of equity will be EUR $166.667 \mathrm{~m}$ and the cost of equity will be $8 \%$ pa (at a risk premium of 3 percentage points); this solution is shown in figure 1 below.

Figure 1: $V_{i}\left(r_{i}\right)$ and $V_{i}^{\text {inv }}\left(r_{i}\right)$ - the valuation solution

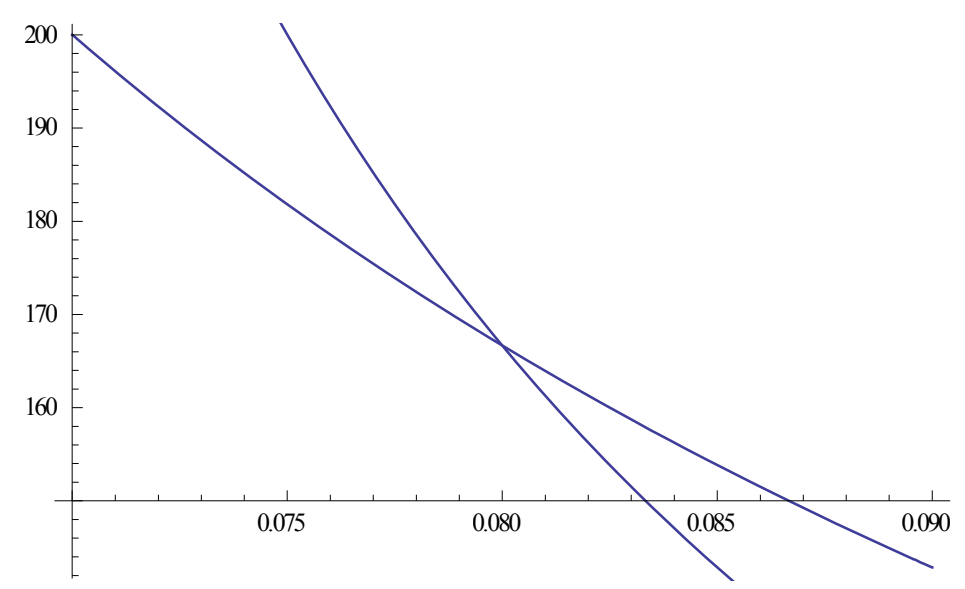

Own calculations, parameter values $\left\{\mathrm{C}_{\mathrm{i}}, \mathrm{g}_{\mathrm{i}}, \mathrm{r}_{\mathrm{f}}, \alpha, \sigma_{\mathrm{Ci}}\right\}=\{10,2 \%, 5 \%, 1,5\}$, solution $\left\{\mathrm{V}_{\mathrm{i}}, \mathrm{r}_{\mathrm{i}}\right\}=\{166.67,8 \%\}$. The steeper of the two functions is $V_{i}^{\text {inv }}\left(r_{i}\right)$ ( since $\left.r_{f}>g_{i}\right)$.

19

The figures presented illustrate the derivation of the solution, the proof of its uniqueness, and parameter sensitivity. All figures were rendered by numerical calculation using Mathematica 8.0 (C) Wolfram Research, Inc.). 
The next two figures illustrate the sensitivity of the solution shown in figure 1 with respect to changing cash flow volatility $\sigma_{\mathrm{Ci}}$.

Figure 2: $\nabla_{i}\left(\sigma_{C i}\right)$

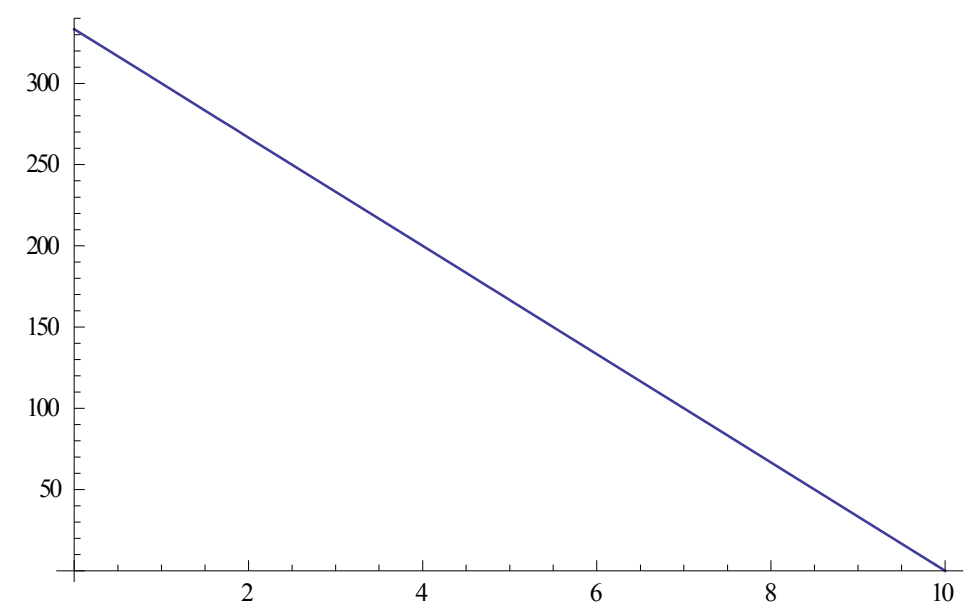

Own calculations, parameter values $\left\{\mathrm{C}_{\mathrm{i}}, \mathrm{g}_{\mathrm{i}}, \mathrm{r}_{\mathrm{f}}, \alpha\right\}=\{10,2 \%, 5 \%, 1\}$.

Figure 3: $\widehat{r}_{\mathrm{i}}\left(\sigma_{\mathrm{Ci}}\right)$

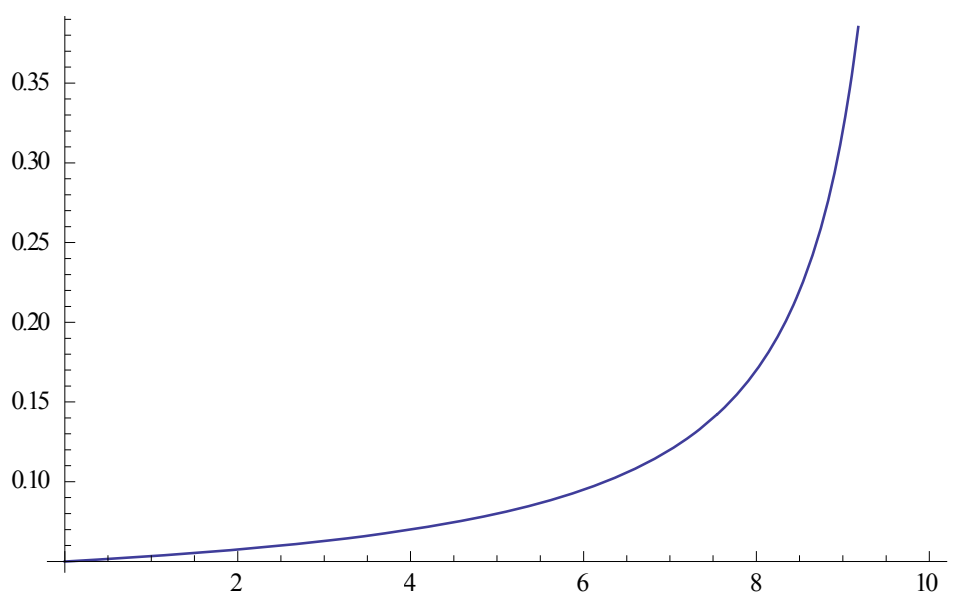

Own calculations, parameter values $\left\{\mathrm{C}_{\mathrm{i}}, \mathrm{g}_{\mathrm{i}}, \mathrm{r}_{\mathrm{f}}, \alpha\right\}=\{10,2 \%, 5 \%, 1\}$. 